Full title:

\title{
Residential Energy Environmental Kuznets Curve in the EU-28
}

\author{
María del P. Pablo-Romero ${ }^{\mathrm{a}}$ and Antonio Sánchez-Braza ${ }^{\mathrm{b}}$
}

Authors:

María del P. Pablo-Romero and Antonio Sánchez-Braza

Information about authors:

\section{María del P. Pablo-Romero}

Department of Economic Analysis and Political Economy

Faculty of Economics and Business Sciences, University of Seville

Ramón y Cajal 1, 41018 Seville, Spain

Associate Reseacher, Universidad Autónoma de Chile, Chile

Tel.: +34 954557 611. Fax: +34954 557629

mpablorom@us.es

Antonio Sánchez-Braza (corresponding author)

Department of Economic Analysis and Political Economy

Faculty of Economics and Business Sciences, University of Seville

Ramón y Cajal 1

41018 Seville, Spain

Tel.: +34 954557 529. Fax: +34 954557629

asb@us.es

\section{Acknowledgments}

The authors acknowledge the financial support received from the ECO2014-56399-R Project of the Spanish Ministry of Economy and Competitiveness, the SEJ-132 project of the Andalusian Regional Government, and the "Cátedra de Economía de la Energía y del Medioambiente" (Chair of Energy and Environmental Economics) of the University of Seville and the "Fundació Roger Torné". 
RESIDENTIAL ENERGY ENVIRONMENTAL KUZNETS CURVE IN THE EU-28

\begin{abstract}
:
Controlling residential energy consumption is crucial to reduce $\mathrm{CO}_{2}$ emissions, as it has an important energy-saving potential, and its environmental controls are difficult to displace offshore. The aim of this study is to analyze the relationships between residential energy consumption and income for the EU-28 countries, in the period 19902013. For this purpose, residential energy environmental Kuznets curves (EKC) are estimated by using panel data techniques. In order to take into account the heterogeneity among countries, a multilevel mixed-effects model is used. The elasticities of residential energy consumption with respect to income are calculated for each year and country, analyzing the different behavior between countries. Obtained results show that the EKC hypothesis is confirmed for the residential sector in the EU-28 countries. Moreover, the results also show that the turning point has been reached in Denmark, Luxembourg, Finland, The Netherlands, and Sweden. Eastern EU-28 countries average elasticity evolution is almost constant through the period, being around 0.25 . The rest of the EU28 countries have a clear decreasing average elasticity evolution trend with lower values around 0.10 at the end of the period.
\end{abstract}

\title{
Keywords:
}

Environmental Kuznets Curve, residential energy consumption, EU-28 countries, panel data, multilevel mixed-effects models, energy consumption-income elasticities. 
RESIDENTIAL ENERGY ENVIRONMENTAL KUZNETS CURVE IN THE EU-28

\section{Introduction}

At the Paris climate conference (COP21) in 2015, 195 Governments worldwide agree to set out an action plan to avoid climate change by limiting global warming to well below $2^{\circ} \mathrm{C}$ [1]. All countries have common responsibilities when it comes to climate change, although these responsibilities are differentiated depending on their particular prosperity. Thus, each country shall communicate its comprehensive Intended Nationally Determined Contributions (INDCs) which outlines the climate actions they intend to take, and the targets they have to reach under the new international agreement. Additionally, the agreement requires all countries to review the INDCs every five years, being encouraged to gradually raise their targets [2].

The EU has communicated its INDCs, in which it is indicated that the EU and its Member States are committed to a binding target of at least a $40 \%$ domestic reduction in greenhouse gas emissions by 2030 compared to 1990. This target goes beyond its current undertaking of a $20 \%$ emission reduction commitment by 2020 . Likewise, it is in line with the EU objective to reduce its emissions by $80-95 \%$ by 2050 compared to 1990, in line with the philosophy of the latest IPCC report [3].

In order to implement the $40 \%$ emissions reduction target by 2030 , the EU is already undertaking several actions to curb $\mathrm{CO}_{2}$ emissions which are basically related to energy use and production, transport, land-use and agriculture, sustainable cities and others. Nevertheless, the energy actions may be considered the most important, as more than $80 \%$ of total emissions in the EU-28 are currently caused by energy use (industry, services, households, transport) and energy production. The main energy consumer 
sector for 2014 was transport, which accounted for $32 \%$ of total energy use, with households accounting for $27 \%$, industry $25 \%$ and services $14 \%$ [4].

From 1990 to 2014, the service and transport sector energy use average annual growth rates were 0.29 and 0.24 per cent, respectively, while the industry and residential energy rates were -0.25 and -0.03 . Several authors have pointed out that industry energy consumption reductions, and therefore industry emissions, may have been partially achieved because they have displaced energy intensive industries offshore, where environmental standards are quite low [5]. Nevertheless, residential energy consumption is difficult (or even impossible) to displace offshore. Therefore the applied energy policies may be more globally-effective in this sector than in others, thus, the analysis of the evolution of residential energy use in EU-countries becomes interesting. Nonetheless, despite the importance of the residential energy sector, there are very few studies which analyze its evolution, its relationships with respect to income or the differences observed among a group of countries. Most studies referring to residential energy are focused on the role of the economic behavior of resident households. Thus, to our knowledge, the only study comparing the residential energy trend for a group of countries is that by Nejat et al. [6], which refers to ten countries accounting for twothirds of global $\mathrm{CO}_{2}$ emissions. The study reviews the status and current trends of energy consumption, $\mathrm{CO}_{2}$ emissions and energy policies in the residential sector. Additionally, some studies refer to the residential energy consumption in specific countries, such as the studies by Štreimikienè [7] focused on Lithuania, and by Heinonen and Junnila [8] related to Finland, among others.

The aim of this study is to analyze the relationships between residential energy consumption and income for the EU-28 countries in the period 1990-2013. For this purpose, residential energy environmental Kuznets curves (EKC) are estimated 
considering two approaches in order to take into account the heterogeneity among the EU-28 countries. Firstly, a control variable representing the possible effect of urbanization in the residential energy consumption was included in the model, as several studies consider that urbanization may affect residential energy use [8-9]. Secondly, as Piaggio and Padilla [10] questioned the suitability of assuming the same functional form and parameters across countries, a multilevel mixed-effects model is used. This model allows more flexibility to be added to the estimated function by including random terms by countries in the coefficients [11-13]. Finally, the elasticities of residential energy consumption with respect to income are calculated for each year and country, analyzing whether there is a different behavior between countries. The elasticities are calculated as in Pablo-Romero and Sánchez-Braza [14].

The EKC hypothesis states that there is an increasing relationship between economic growth and pollution until a certain turning point, after which the relationship between both variables becomes negative [15]. The potential validity of the EKC hypothesis has been extensively tested. In most of these cases, the EKC is tested using total $\mathrm{CO}_{2}$ emissions and per capita income. Few studies refer to sector-level analysis. Among them may be highlighted the studies by Fujii and Managi [16], Wang et al. [17], and Fu and Zhang [18] testing the EKC hypothesis for some industries; those by Cole et al. [19], Hilton and Levinson [20], Cox et al. [21], Abdallah et al. [22], Chandran and Tang [23], Azlina et al. [24], and Shahbaz et al. [25] concerning the EKC studies on the transport sector; and those by Coderoni and Esposti [26], Wei et al. [27], and Liutao [28] for the agricultural sector. Additionally, some studies refer to residential $\mathrm{CO}_{2}$ emissions or energy consumption. Among these, the study by Bohne et al. [29] provides a global overview of residential building energy consumption in eight climate zones. Likewise, 
the study by Yin et al. [30] estimates long-run and short-run elasticities of residential electricity consumption in China to test the EKC.

This study enlarges the previous EKC literature by focusing the analysis on the total energy consumption of the residential sector, upon which the application of energy policies may be more globally-effective. Additionally, to our knowledge, this is the first work to assess the total residential energy EKC hypothesis among the EU-28 countries. In doing so, the main innovation of the paper is the improvement of the methodology used to test the EKC hypothesis. In this paper multi-level panel data techniques have been used. This methodology allows the heterogeneity among the EU countries to be considered. Thus, knowledge of these relationships is important to better implement energy and environmental policies oriented to reducing global carbon emissions.

\section{Methodology}

The general specification model for testing the EKC is expressed as follows:

$$
E_{i t}=A_{i t}+\beta_{1} Y_{i t}+\beta_{2} Y_{i t}^{2}+\beta_{3} Y_{i t}^{3}+e_{i t}
$$

where $E$ is an environmental indicator in per capita terms, in this case residential energy consumption per capita expressed in logarithms, $Y$ is the independent variable of income per capita expressed in logarithms, in this case GDP, $A$ represents the sum of the time effect and country or individual effect and $i$ and $t$ denote countries and years, respectively. Finally, $e$ is a random error term.

Several econometric problems have been observed in previous studies when estimating the EKCs. Firstly, some authors such as Narayan and Narayan [31] have perceived multicollinearity problems among the explanatory variables. This seems rather obvious 
as the EKC model contains GDP and the square of GDP (or even cubic GDP), with the authors proposing examining the EKC hypothesis based on the short-run and long-run income elasticities to avoid the problems. Additionally, Narayan et al. [32] propose a new approach based on the cross-correlation estimates. The authors state that if there is a positive cross-correlation between the current level of income and the past level of emissions, and a negative cross-correlation between the current level of income and future emissions, the EKC hypothesis will hold. Therefore, both approaches test the EKC avoiding the use of square and cubic GDP terms.

In this paper, the severity of multicollinearity among the explanatory variables was first quantified by using the values of the variance inflation factors (VIFs). In general, it is considered that the variance inflation factor (VIF) value for each variable should not exceed the value 10, with a maximum VIF of 5 being a more stringent criterion [33]. Once this problem was shown, the data were converted to deviations from the geometric mean of the sample to mitigate it. Therefore, square and cubic GDP terms are maintained in the specification model. This change implies that the $\beta_{1}$ coefficient now represents the per capita residential energy consumption elasticity with respect to income per capita at the point of the sample which makes income per capita be equal to its geometric mean, that is to say, in the central point of the sample $[\mathbf{1 4 , 3 4 ]}$. This transformation avoids the multicollinearity among the variables, which is tested again by using the VIF values.

Using a topline over variables to indicate these deviations, it is possible to rewrite (1), as follows,

$$
\bar{E}_{i t}=\bar{A}_{i t}+\beta_{1} \bar{Y}_{i t}+\beta_{2} \bar{Y}_{i t}^{2}+\beta_{3} \bar{Y}_{i t}^{3}+e_{i t}
$$


Additionally, other authors have pointed out possible spurious estimates in some previous studies when testing the EKC [35]. In order to avoid spurious estimates, the stochastic nature and properties of the variables were examined. Firstly, cross-section dependence in the data was tested by using the parametric testing procedure proposed by Pesaran [36], under the null hypothesis of cross-section independence. Secondly, the test proposed by Pesaran [37], the CIPS test, was used to investigate the presence of unit roots. This method is based on augmenting the ADF regression with the lagged crosssectional mean and its first difference to capture the cross-sectional dependence that arises through a single-factor model. Under the null of non-stationarity, the test statistic has a non-standard distribution. Finally, the error correction based on panel cointegration tests proposed by Westerlund [38] was implemented to test the existence of a structural long-run relationship among the variables. As stated in Persyn and Westerlund [39], these tests are enough to accommodate cross-sectional dependence through bootstrapping. The null hypothesis of these tests is the absence of cointegration. The Gt and Ga statistics test whether cointegration exists for at least one individual, while the Pt and Pa statistics test whether cointegration exists for the panel in total.

Taking into account the previous tests results, the data were also transformed into first differences, therefore being similar to expressing the EKC in terms of long-run growth rates [40]. Using $\Delta$ to indicate first differences, it is possible to rewrite (2) as follows,

$\overline{\Delta E}_{i t}=\overline{\Delta A}_{i t}+\beta \Delta_{1} \bar{Y}_{i t}+\beta_{2} \Delta \bar{Y}_{i t}^{2}+\beta_{3} \Delta \bar{Y}_{i t}^{3}+e_{i t}$

where $\overline{\Delta A}_{i t}=\delta_{t}$.

Finally, some authors, such as Piaggio and Padilla [10], have questioned the panel data estimates due to the heterogeneity of the sample. With the aim of reducing this heterogeneity, two approaches were considered. Firstly, a control variable $(C)$ was 
included in (3). In this case, $C$ represents the share of urban population with respect to total population. This variable represents the possible effect of urbanization in the residential energy consumption. Several studies, such as those by Heinonen and Junnila [8] and Wiedenhofer et al. [9], state that urbanization may affect the energy use in the residential sector, with it being less energy-intensive in rural areas. Therefore, the equation to be estimated may be reformulated as

$\overline{\Delta E}_{i t}=\overline{\Delta A}_{i t}+\beta \Delta_{1} \bar{Y}_{i t}+\beta_{2} \Delta \bar{Y}_{i t}^{2}+\beta_{3} \Delta \bar{Y}_{i t}^{3}+\phi \Delta \bar{C}_{i t} e_{i t}$

Additionally, as Piaggio and Padilla [10] questioned the suitability of assuming the same functional form and parameters across countries, it may be appropriate to estimate (4) allowing the $\beta$ coefficients to not be constant, but to vary by including a random term in the $\beta$ coefficients, in which the coefficient is considered as a latent variable, improving the efficiency of the econometric estimates [41].

Therefore, $\beta$ coefficients may be defined as

$$
\begin{aligned}
& \beta_{1 i}=\gamma_{1}+\mu_{1 i} \\
& \beta_{2 i}=\gamma_{2}+\mu_{2 i} \\
& \beta_{3 i}=\gamma_{3}+\mu_{3 i}
\end{aligned}
$$

where $\mu$ represents the random effects for the individual observations.

Thus, equation (4) may be expressed as

$$
\overline{\Delta E}_{i t}=\overline{\Delta A}_{i t}+\gamma_{1} \Delta \bar{Y}_{i t}+\mu_{1 i} \Delta \bar{Y}_{i t}+\gamma_{2} \Delta \bar{Y}_{i t}^{2}+\mu_{2 i} \Delta{\overline{Y_{i t}}}^{2}+\gamma_{3} \Delta \bar{Y}_{i t}^{3}+\mu_{3 i} \Delta \bar{Y}_{i t}^{3}+\phi \Delta \bar{C}_{i t}+e_{i t}
$$

where (6) may be estimated by using multilevel mixed-effects models [11-13]. Likelihood-ratio tests were performed in order to compare different models: a model with a random term in the $\beta_{1}$ coefficient versus a model without random terms in $\beta$ 
coefficients, a model with a random term in the $\beta_{1}$ and $\beta_{2}$ coefficients versus a model with a random term in the $\beta_{1}$ coefficient, and a model with a random term in the $\beta_{1,} \beta_{2}$ and $\beta_{3}$ coefficients versus a model with a random term in the $\beta_{1}$ and $\beta_{2}$ coefficients; the first test being similar to testing the adequacy of considering random effects in coefficients instead of constant coefficients (similar to equation (4)) .

Once the equation (4) or (6) is estimated, the $\beta$ coefficients obtained may inform about the relationships between the $E$ and $Y$ variables. If all $\beta$ coefficients are positive, then an increasing relationship exists between $E$ and $Y$. However, if $\beta_{1}>0, \beta_{2}<0$ and $\beta_{3} \leq 0$ the EKC exists [42]. In this case, a threshold or a turning point may be calculated, making the elasticity of $E$ with respect to $Y$ equal to zero. This elasticity may be calculated for each year and country as follows:

$$
\text { elas }_{i t}=\beta_{1}+2 \beta_{2} \bar{Y}_{i t}+3 \beta_{3} \bar{Y}_{i t}^{2}
$$

These elasticities measure the residential energy consumption sensitivity with respect to a change in the income per capita, for each year and country. Thus, it is a measure of the responsiveness of $E$ to an increase in $Y$. Therefore, these elasticities allow the possibility of analyzing different behavior between countries. In that regard, it is worth noting that the elasticity of $E$ with respect to $Y$ is much more flexible when $\beta$ coefficients are obtained from (6) than from (4).

\section{Data}

The data in this study came from two different sources. The first is the International Energy Agency database [43], which contains energy statistics of all kinds, including on supply, trade, stocks, production and demand. The second is The Word Bank 
database [44], which provides collections of time series data on a variety of variables and topics. Both database are broken down by a large number of countries.

According to the data available from the two selected databases, this study covers 28 EU countries (Austria, Belgium, Bulgaria, Croatia, Cyprus, Czech Republic, Denmark, Estonia, Finland, France, Germany, Greece, Hungary, Ireland, Italy, Latvia, Lithuania, Luxembourg, Malta, the Netherlands, Poland, Portugal, Romania, Slovakia, Slovenia, Sweden, Spain, and the UK). The time period studied only ranges from 1990 to 2013 , due to the lack of data continuity for the years 2013 to 2016, for all the variables considered.

\subsection{Residential energy consumption}

Total final energy consumption can be broken down into industry, transport, others (including agricultural and forestry, fishing, commercial and public services, residential and non-specified total energy use) and non-energy uses. In this study, it is the energy used in the domestic setting that was analyzed. The information about the residential energy consumption comes from the Energy Balances included in the International Energy Agency database [43]. This variable is expressed in terms of net calorific value in thousand tonnes of oil equivalent (ktoe), and was converted into natural logarithms.

\subsection{Gross Domestic Product}

Gross Domestic Product (GDP) values came from the World Development Indicators included in The World Bank national accounts data files [44]. In order to correct the data for the corresponding price levels and exchange rates, all the figures 
used are formulated in millions of 2005 constant U.S. Dollars. This variable was also converted into natural logarithms.

\subsection{Total population and share of urban population}

Population data are also obtained from The World Bank national accounts data files [44]. The figures are in millions of persons and midyear estimates for each year, and are converted into natural logarithms. Furthermore, residential energy consumption and GDP variables expressed in logarithmic terms were converted into per capita terms by using this population data series.

The share of urban population is also taken from this database in order to construct the urban population variable. This variable is defined as the percentage of people living in urban areas over total population, and is included in the estimated model as a control variable.

\subsection{Descriptive analysis}

Table 1 shows the main descriptive statistics of the variables: Residential energy consumption per capita $(E)$ and GDP per capita $(Y)$, both in natural logarithms, and the share of urban population as a percentage of total population $(C)$. The overall statistics refer to the whole sample, while the within statistics refer to each country and to the variation from each country's average. If a variable does not change over time, its within standard deviation will be zero. The between statistics refer to the standard deviation, and minimum and maximum of the averages for each country. Table 1 shows that the typical standard deviation of the data is higher across countries than across time for all variables. 


\section{Table 1}

Descriptive statistics.

\begin{tabular}{|c|c|c|c|c|c|c|}
\hline Variables & & Mean & Std. Dev. & Min. & Max. & Observations \\
\hline \multirow{3}{*}{$\begin{array}{l}\text { Residential } \\
\text { energy } \\
\text { consumption } \\
\text { per capita in } \\
\text { logs. }\end{array}$} & overall & 6.280401 & 0.453003 & 5.057156 & 7.325115 & $N=672$ \\
\hline & between & & 0.446091 & 5.242471 & 7.068627 & $\mathrm{n}=28$ \\
\hline & within & & 0.114174 & 5.828108 & 6.722167 & $\mathrm{~T}=24$ \\
\hline \multirow{3}{*}{$\begin{array}{c}\text { GDP per } \\
\text { capita in logs. }\end{array}$} & overall & 2.860086 & 0.829622 & 0.900824 & 4.455800 & $N=672$ \\
\hline & between & & 0.819726 & 1.199409 & 4.238931 & $\mathrm{n}=28$ \\
\hline & within & & 0.198382 & 2.322466 & 3.365368 & $\mathrm{~T}=24$ \\
\hline \multirow{3}{*}{$\begin{array}{l}\text { Share of } \\
\text { urban } \\
\text { population }\end{array}$} & overall & 0.712421 & 0.118734 & 0.479150 & 0.977760 & $N=672$ \\
\hline & between & & 0.119294 & 0.504460 & 0.971592 & $\mathrm{n}=28$ \\
\hline & within & & 0.018828 & 0.609605 & 0.815475 & $\mathrm{~T}=24$ \\
\hline
\end{tabular}

Moreover, the graphs in Figure 1 show the evolution of residential energy consumption per capita and GDP per capita variables by country (represented by different colored lines), from 1990 to 2013 , for the 28 countries that make up the sample.

\section{[Figure 1]}

The values in Figure 1 are spread around the thick black line that represents each year's average value. It shows an almost constant trend in terms of EU-28 median spline values, contrasting with significant differences evident between countries throughout the period, with a wide dispersion for the countries below and above this average. Thereby, the countries below the average trend show very different evolutions, with a clear increasing trend in most cases. There are two particular countries, Malta and Cyprus (lower graph), the first with the lowest value of residential energy consumption per capita and the second with very low initial values accompanied by a 
strong increase in the latter years of the considered period. Other countries with lower residential energy consumption per capita values are Portugal and Spain (upper graph). On the contrary, among the countries in the higher plots of residential energy consumption per capita values are Luxembourg, Finland, and Belgium, followed by Sweden, Denmark, Germany, and Austria (upper graph).

Likewise, Figure 2 shows the evolution of GDP in per capita terms. It has a positive growth rate throughout the period, while it can be seen that large differences exist between countries. A pronounced decrease in GDP per capita is also shown from 2009, reflecting the deep recession that gripped most European countries. Furthermore, the lower graph shows that countries with lower GDP per capita (Bulgaria, Romania, Latvia, Lithuania, Poland, and Estonia) have more of an upward trend. On the other hand, countries with the highest levels of GDP per capita, in the upper graph, (Luxembourg, Denmark, Ireland, Sweden, and the Netherlands), display a much smoother upward trend.

\section{[Figure 2]}

\section{Results and discussion}

\subsection{Multicollinearity, cross-section dependence, unit root and cointegration tests}

In order test the severity of multicollinearity among explanatory variables used in the EKC estimate, VIF values were obtained for the variables, both with and without being converted to deviations from the geometric mean of the sample. These VIF values are reported in Table 2. As observed, the VIF values do not exceed the value of 5 for any converted explanatory variable, ruling out possible problems of multicollinearity when 
considering the variables expressed in terms of deviations with respect to its geometric mean.

Table 2

Variance inflation factors.

\begin{tabular}{ccc}
\hline Variables & $\begin{array}{c}\text { VIF } \\
\text { (variables) }\end{array}$ & $\begin{array}{c}\text { VIF } \\
\text { (deviations from the } \\
\text { geometric mean) }\end{array}$ \\
\hline$Y$ & 658.94 & 3.64 \\
$Y^{2}$ & 2941.04 & 1.66 \\
$Y^{3}$ & 879.71 & 4.99 \\
$C$ & 1.20 & 1.21 \\
\hline Mean VIF & 1120.22 & 2.89 \\
\hline
\end{tabular}

Table 3 shows the Pesaran [36] CD test results for cross-section dependence in panel time-series. Empirical results show that the null hypothesis of cross-sectional independence in our panel is rejected for all series. Therefore, the Pesaran [37] second generation panel unit roots tests (CIPS tests) were calculated. Table 4 shows the CIPS tests applied to the variables involved, in levels and first differences. The results show that variables are I(1), as they are stationary in first differences and non-stationary in levels. Finally, Table 5 shows the computed values of the Westerlund co-integration tests obtained through bootstrapping (400 replications), as cross-sectional independence is rejected for all series. The results show that the null hypothesis of no co-integration cannot be rejected. Therefore, it is convenient to estimate the model by using firstdifferences.

\section{Table 3}

Panel cross-section dependence tests.

\begin{tabular}{cc}
\hline Variables & CD test \\
\hline$Y$ & $85.96^{* * *}$ \\
$Y^{2}$ & $85.75^{* * *}$ \\
$Y^{3}$ & $85.43^{* * *}$ \\
$C$ & $15.56^{* * *}$ \\
\hline
\end{tabular}

Note: $* * *$ denotes significance at the $1 \%$ level. 


\section{Table 4}

CIPS unit root test in the presence of cross-section dependence.

\begin{tabular}{ccccc}
\hline Variables & \multicolumn{2}{c}{ Level } & \multicolumn{2}{c}{ First Differences } \\
\hline & Intercept & Intercept and trend & Intercept & Intercept and trend \\
\hline$E$ & $-2.140^{*}$ & -2.427 & $-4.471^{* * *}$ & $-4.611^{* * *}$ \\
$Y$ & -2.050 & -2.119 & $-3.615^{* * *}$ & $-4.089^{* * *}$ \\
$Y^{2}$ & -0.603 & -1.108 & $-2.947^{* * *}$ & $-3.440^{* * *}$ \\
$Y^{3}$ & $-2.105^{*}$ & $-2.584^{*}$ & $-3.525^{* * *}$ & $-3.643^{* * *}$ \\
$C$ & $-2.142^{*}$ & $-2.601^{*}$ & $-3.707^{* * *}$ & $-4.592^{* * *}$ \\
\hline
\end{tabular}

Note: $t$-bar statistics $* * *$ denotes significance at the $1 \%$ level, $* *$ at the $5 \%$ level and $*$ at the $10 \%$ level. Number of lags included in each individual regression calculated with an iterative process from 0 to 3 based on $\mathrm{F}$ joint test. The truncated version of the test is applied which limits the undue influence of extreme values that could occur when the time dimension is small.

\section{Table 5}

Results of the cointegration tests for cross-sectionally dependent panels.

\begin{tabular}{cccccc}
\hline \multirow{2}{*}{ Dependent variable } & Independent variables & \multicolumn{4}{c}{ Cointegration tests } \\
& $Y, Y^{2}, Y^{3}, C$ & Gt & Pa & Ga \\
\hline$E$ & & -2.375 & -1.567 & -12.452 & -5.536 \\
& $Y, Y^{2}, C$ & -3.728 & -2.032 & -14.112 & -5.292 \\
\hline
\end{tabular}

Note: The test regression is fitted with a constant and trend, the AIC is used to determine an optimal lag and lead length with the kernel bandwidth being set according to the rule 4(T/100)2/9. The $p$-values are for a one-sided test based on 400 bootstrap replications. *** denotes significance at the $1 \%$ level, ** at the $5 \%$ level and $*$ at the $10 \%$ level.

\subsection{Single and multi-level model estimates}

Table 6 shows the results of estimating the equations (4) and (6) to test the EKC existence for the residential energy consumption in the EU-28, from 1990 to 2013. Column (a) shows the estimate results when the feasible generalized least squares (FGLS) method is used, while columns (b) and (c) show the estimate results when a multilevel mixed model is used. Column (b) shows the results when a random term is included in the $\beta_{1}$ coefficient and column (c) when a random term is also included in the $\beta_{2}$ coefficient. 


\section{Table 6}

Estimate results of equation (4) and (6).

\begin{tabular}{|c|c|c|c|}
\hline & $\begin{array}{c}\text { FGLS } \\
\text { Equation [4] } \\
\text { (a) }\end{array}$ & $\begin{array}{c}\text { Multilevel model } \\
\text { Equation (6) with } \\
\text { a random term in } \beta_{1} \\
\text { (b) }\end{array}$ & $\begin{array}{c}\text { Multilevel model } \\
\text { Equation (6) with } \\
\text { random terms in } \beta_{1} \text { and } \beta_{2} \\
\text { (c) }\end{array}$ \\
\hline$Y$ & $\begin{array}{l}0.277 * * * \\
(0.022)\end{array}$ & $\begin{array}{l}0.280^{* * *} \\
(0.115)\end{array}$ & $\begin{array}{l}0.280 \text { *** } \\
(0.117)\end{array}$ \\
\hline$Y^{2}$ & $\begin{array}{l}-0.101^{* * *} \\
(0.014)\end{array}$ & $\begin{array}{l}-0.112 * * * \\
(0.034)\end{array}$ & $\begin{array}{l}-0.114^{* * *} \\
(0.033)\end{array}$ \\
\hline$Y^{3}$ & $\begin{array}{l}-0.062 * * * \\
(0.007)\end{array}$ & $\begin{array}{l}-0.051 * * \\
(0.026)\end{array}$ & $\begin{array}{l}-0.050 * * \\
(0.026)\end{array}$ \\
\hline$s d\left(\beta_{1}\right)$ & - & $\begin{array}{l}0.221 * * * \\
(0.083)\end{array}$ & $\begin{array}{c}0.188^{*} \\
(0.109)\end{array}$ \\
\hline$s d\left(\beta_{2}\right)$ & - & - & $\begin{array}{l}0.028 \\
(0.046)\end{array}$ \\
\hline
\end{tabular}

Note: Standard errors are shown in parenthesis, $* * *$ denotes significance at the $1 \%$ level, $* *$ at the $5 \%$ level and $*$ at the $10 \%$ level. All estimates include time dummies and the control variable C.

Column (a) in Table 6 shows the results of estimating (4) by using the FGLS method in the presence of autocorrelation, heteroscedasticity and contemporaneous correlation, according to the results of the Wooldridge [45] test for autocorrelation, the Wald test for homoscedasticity, proposed in Greene [46], and the Pesaran [36] test for contemporaneous correlation. Column (a) shows that $\beta_{1}$ coefficients are positive and significant, therefore, in the central point of the sample the elasticity is positive, thus, increases in GDP per capita increase residential energy consumption per capita. This coefficient is less than one (0.277), meaning that the increase of residential energy consumption per capita is less than proportional to the increase of GDP per capita. Table 6 also shows that both $\beta_{2}$ and $\beta_{3}$ coefficients are negative and significant. Therefore, the results show that the EKC hypothesis is confirmed, as according to Dinda [42], if $\beta_{1}>0, \beta_{2}<0$ and $\beta_{3}<0$, then an inverted $U$ relationship (EKC) exists. 
Columns (b) and (c) in Table 6 show the results of estimating (6) by using a multilevel mixed model. Column (b) shows the estimate including a random term in the $\beta_{1}$ coefficient allowing it to vary randomly across countries, as shown in (6), with the aim of defining a more flexible model. Additionally, column (c) also includes a random term in the $\beta_{2}$ coefficient to make the equation even more flexible, as defined in (6). Both estimates are obtained using the maximum likelihood (ML) method, allowing heteroskedasticity and correlations to be modelled within lowest-level groups. The random effects are not directly estimated, but can be obtained according to their estimated variances and covariances. Columns (b) and (c) additionally included the estimates of the standard deviations $\left(\operatorname{sd}\left(\beta_{1}\right)\right.$ and $\left.\operatorname{sd}\left(\beta_{2}\right)\right)$ of the $\beta_{1}$ and $\beta_{2}$ coefficients.

Results obtained by using a multilevel mixed model show that the values of the $\beta_{1}$ coefficients depend on the values of $\gamma_{1}$ and $\mu_{1 i}$, so that they vary randomly across countries, as the standard deviation of $\beta_{1}$ is significantly different to zero. Nevertheless, the standard deviation of $\beta_{2}$ is not significantly different to zero. In order to test if it is better or not to include $\beta_{2}$ random variation in the model, a likelihood-ratio test (LR test) was performed. This test compares the log-likelihood of both models (with and without $\beta_{2}$ random variation), testing the null hypothesis that there is no significant difference between them. As the LR test value is equal to $\operatorname{chi}^{2}(2)=0.37$, when comparing estimates in columns (b) and (c), the null hypothesis may not be rejected. Therefore, the $\beta_{2}$ random variation may be omitted. Additionally, the LR test was used to compare this multilevel model with a single one in which random effects are not included. In this case, the null hypothesis may be rejected $\left(\operatorname{chi}^{2}(2)=7.55\right)$, and therefore it can be inferred that the multilevel model is preferred to the single model. 
The obtained results represented in column (b) in Table 6 show that the $\gamma_{1}$ coefficient is positive and significant with a value less than one (0.280). In order to calculate the values of $\beta_{1}$ coefficients, it is necessary to previously obtain the random effects $\left(\mu_{1 i}\right)$ corresponding to each country $i$, according to [5]. Table 7 shows the $\beta_{1}$ values for each country. Latvia has the lowest value, followed by Poland and Slovenia. Conversely, Cyprus has the highest values, followed by Romania and Malta. It is worth noting that all $\beta_{1}$ values are positive. Column (b) in Table 6 also shows that the $\gamma_{2}$ coefficient is negative and significant. This coefficient is equal to $\beta_{2}$ as random effects were not significant. Likewise, it is shown that the $\gamma_{3}$ coefficient, which is equal to $\beta_{3}$, is also negative and significant. Therefore, the EKC hypothesis is confirmed.

The EKC threshold or turning point may be calculated making the elasticity of residential energy consumption per capita with respect to GDP per capita equal to zero. According to (7), the elasticity varies between countries and across time. In order to obtain these elasticities, the results from estimates in column (b) in Table 6 were used. Therefore, elasticities were calculated as follows:

$$
\text { elas }_{i t}=\beta_{1 \mathrm{i}}-2 * 0.112 * \bar{Y}_{i t}-3 * 0.051 * \bar{Y}_{i t}^{2}
$$

where $\beta_{1 i}$ values are from Table 7 .

The average elasticity values across time for each country are also shown in Table 7. Cyprus has the highest values at around 0.66, while Luxembourg has the lowest value at around -0.32. Denmark, Luxembourg, Finland, the Netherlands, and Sweden have negative average values, showing that they have passed the EKC turning point. Therefore, the income increases in these countries are provoking residential energy consumption decreases. 


\section{Table 7}

$\beta_{1}$ coefficient and average elasticity of Residential Energy Consumption per capita with respect to GDP per capita by countries.

\begin{tabular}{cccccc}
\hline Country & $\beta_{1 i}$ & $\overline{e l a s}_{i}$ & Country & $\beta_{1 i}$ & $\overline{\text { elas }}_{i}$ \\
\hline AUSTRIA & 0.319 & 0.084 & ITALY & 0.224 & 0.063 \\
BELGIUM & 0.278 & 0.063 & LATVIA & 0.005 & 0.038 \\
BULGARIA & 0.253 & 0.196 & LITHUANIA & 0.178 & 0.232 \\
CROATIA & 0.336 & 0.411 & LUXEMBOURG & 0.270 & -0.323 \\
CYPRUS & 0.709 & 0.666 & MALTA & 0.412 & 0.452 \\
CZECH REPUBLIC & 0.337 & 0.395 & NETHERLANDS & 0.217 & -0.053 \\
DENMARK & 0.286 & -0.054 & POLAND & 0.044 & 0.108 \\
ESTONIA & 0.258 & 0.320 & PORTUGAL & 0.284 & 0.283 \\
FINLAND & 0.213 & -0.005 & ROMANIA & 0.509 & 0.508 \\
FRANCE & 0.294 & 0.096 & SLOVAK REPUBLIC & 0.327 & 0.396 \\
GERMANY & 0.234 & 0.023 & SLOVENIA & 0.084 & 0.101 \\
GREECE & 0.389 & 0.366 & SPAIN & 0.397 & 0.315 \\
HUNGARY & 0.206 & 0.280 & SWEDEN & 0.184 & -0.086 \\
IRELAND & 0.311 & 0.026 & UNITED KINGDOM & 0.291 & 0.059 \\
\hline
\end{tabular}

Figure 3 shows the evolution through the studied period of the elasticity values obtained for each country, represented by different colored lines. The lower graph in Figure 3 shows the evolution of these elasticities for the Eastern EU-28 countries while the upper graph in Figure 3 shows these elasticities for the rest of the EU-28 countries. The values are spread around a thick black line that represents each year's average value for each country group.

[Figure 3] 
The lower graph in Figure 3 shows that the Eastern EU-28 countries average elasticity evolution is almost constant through the period, being around 0.25 . Country elasticity values range between 0 and 0.5 , always being positive except for Latvia's early years. A notably different evolution of elasticities for countries is observed. Thus, some countries have a nearly constant trend while others have a clear positive trend, as for Romania, Latvia, Bulgaria and Lithuania. Likewise, it is worth noting that Slovenia is the only Eastern EU-28 country with a clear negative trend, although zero value is not reached.

On the other hand, the upper graph in Figure 3 shows that the rest of the EU-28 countries have a clear decreasing average elasticity evolution trend which become stabilized around 0.10 at the end of the period. This value is notably lower than the Eastern countries average value. Likewise, the right graph shows that there is a country group with very similar elasticity values and trend. Beyond these countries, Cyprus, Malta, Portugal and Greece have remarkably higher elasticity values, while Luxembourg has a notably lower value. It is also worth noting that several country elasticities become negative through the period, passing the EKC turning point. Among them, are included Denmark, Finland, Ireland, the Netherlands, Sweden, and finally Germany, at end of the period.

Finally, Figure 4 displays the elasticity values of residential energy consumption per capita with respect to GDP per capita for each GDP per capita level.

\section{[Figure 4]}

The elasticity values show that the ECK is supported, reaching the ECK turning point for a GDP per capita value around 3.5 in logarithmic terms. Below this value, elasticities are positive, rising until a GDP per capita level close to 2. From this value, elasticities start to decrease. Additionally, Figure 4 shows that the elasticity values 
scatter is much higher for GDP per capita levels below 3.5, displaying a higher heterogeneity for lower income levels.

\section{Discussion and policy implications}

Obtained results show that the EKC hypothesis is confirmed for the residential sector in the EU-28 countries. Moreover, they also show that the turning point has been reached in some countries with a high income level. So, in these countries, income increases are provoking residential energy consumption decreases in per capita terms. In this regard, higher income levels may be allowing the purchase of more efficient equipment and appliances, and the construction of buildings with more energy efficient materials, while lower income levels may be limiting these purchases, since, as stated in Vassileva and Campillo [47], the consumers' income is one of the main constraints affecting the

purchase of efficient appliances. Thus, consumers in lower income countries may have difficulty in investing in energy efficient equipment, which, according to Cayla et al. [48], is particularly relevant in the case of purchasing heating systems. Therefore, in order to also achieve residential energy consumption reductions in the poorest EU-28 countries, it may be appropriate to promote economic growth to enhance households' income levels. Additionally, policies such as subsidies, grants or zero-rate loans to favor access to capital for the lower income households may be fitting. Thus, as stated in studies such as that by Mata et al. [49], facilitating the financing of investments in energy-saving measures, and reducing other barriers in consumers' perspectives, will increase the adoption of energy-saving equipment. In that regard, Bartiaux et al. [50] conclude that vertical and horizontal diffusion across social classes can enhance the uptake of residential energy retrofits and other energy saving practices, if they are adequately translated into policy instruments. 
Additionally, the results show clear differences among sample countries, being greater among the Eastern countries. Likewise, these countries have the greatest elasticity values. Therefore, it may be appropriate to introduce more intensive residential energy policies in these countries, including more differentiated policies that allow their specific characteristics to be taken into account. As stated in the ADEME report [51], residential energy efficiency improvements are hindered by various barriers, each of which needs to be addressed by different types of measures, which may be done by developing an adequate balanced policy mix including several types of measures.

Nevertheless, as stated in Galvin [52], most of the Eastern EU countries present 'strong' or even 'backfire' rebound effects, which means that the energy efficiency gains are lost, partially or totally, due to increases in energy service consumption. In that regard, the installation of smart meters which provide consumers with the information and services necessary to optimize their energy consumption could be recommended.

In addition, in order to avoid these rebound effects, programs in energy-efficient refurbishment and energy prices should be considered as valuable energy policy instruments, especially in Bulgaria, Romania, Estonia, Lithuania and Latvia, where, according to Filipović et al. [53], low electricity prices and high energy intensity are jointly observed. Nevertheless, as such states are more exposed to the price factor because households spend relatively more on domestic energy than in the rest of the EU [54], energy poverty risks should also be considered when the energy policy is designed.

In the rest of the EU-28 countries, more homogeneity in elasticity values is observed (with the exception of Cyprus, Greece, Luxembourg, Malta and Portugal). Therefore, a more similar energy policy among them may be appropriate. Countries which have not reached the EKC turning point may focus on the good practices applied in those 
countries in which it has been reached. As stated in Filippini et al. [55], measures such as performance standards of buildings, heating systems and appliances contribute to improved efficiency. Therefore, it is recommended to apply or strengthen these measures in those countries which have not yet reached the EKC turning point. Nevertheless, it is worth noting that standards on the level of energy efficiency of buildings and heating systems may only impact on energy efficiency in the longer term, because the standards usually only apply to new buildings and the construction rates of these buildings are relatively small. Therefore, it is also recommended to apply these standards to buildings for sale.

Related to heating systems, in addition to standards on the level of their energy efficiency, it is also appropriate to promote solar energy in order to substitute conventional energies currently used to produce hot water. In this regard, solar water heaters may represent a good economical and environmental solution, mainly for southern countries which benefit from a good solar irradiation. As stated in the ADEME report [51], solar water heaters may be promoted through financial and fiscal incentives (subsidies, soft loans or tax credits) and regulations. Along this line, the study by Sánchez-Braza and Pablo-Romero [56] leads to the conclusion that the percentage increase in square meters of solar-thermal energy systems installed in buildings in Spanish municipalities, which adopted a tax bonus promotion, ranged from $70.74 \%$ to $98.38 \%$. Nevertheless, in addition to these financial and fiscal incentives, it is worth noting that, recently, the leasing model has also opened up the residential PV market to a new consumer segment, those with a tight cash-flow situation [57]. Therefore, it could be appropriate to facilitate these leasing models.

Finally, it is worth noting that countries which have reached the turning point could also continue decreasing their residential energy use by increasing their income per capita. 
Therefore, it may be recommendable for these countries to focus their efforts on other sectors with higher $\mathrm{CO}_{2}$ emissions.

\section{Conclusions}

The EU has indicated in its INDCs that the EU and its Member States are committed to a binding target of at least a $40 \%$ domestic reduction in emissions by 2030 . Several actions are being undertaking to reach this target, the most important relating to energy, as more than $80 \%$ of total emissions in the EU-28 are caused by energy use. Controlling residential energy consumption may be more globally-effective than other sectors, as residential energy consumption is difficult to displace offshore. Thus, the analysis of the residential energy use evolution in EU-countries becomes interesting.

This study analyzes the relationships between residential energy consumption and income for the EU-28 countries in the period 1990-2013. A residential energy EKC is estimated by using a multilevel mixed-effects model, and residential energy consumption elasticities with respect to GDP per capita are calculated for each year and country.

The obtained results confirm the EKC hypothesis, reaching the ECK turning point for a GDP per capita value of around 3.5 in logarithmic terms. Higher heterogeneity elasticity values are observed for GDP per capita levels below this value. Likewise, notably different values and evolution of elasticities for the EU-28 countries are observed, mainly between Eastern countries and the others.

Eastern EU-28 countries have the greatest elasticity values, with an almost constant average evolution of around 0.25 through the period. Slovenia is the only one with a clear negative trend, although zero value is not reached. Additionally, the results show 
clear differences among these countries' elasticities. Therefore, it may be appropriate to promote more intensive residential energy policies in these countries, including more differentiated policies that allow their specific characteristics to be taken into account.

The rest of the EU-28 countries have a clear decreasing average elasticity evolution trend which becomes stabilized at around 0.10 at the end of the period. Cyprus, Malta, Portugal and Greece have remarkably higher elasticity values. The rest of these countries have more homogeneity in their elasticity values. Therefore, a more similar energy policy among them may be appropriate. It is worth noting that Denmark, Luxembourg, Finland, the Netherlands, and Sweden pass the EKC turning point. Therefore, as income increases in these countries, residential energy consumption decreases. In that sense, countries which have not reached the EKC turning point may focus on the good practices applied in those countries in which it has been reached.

\section{References}

[1] Burleson E. Paris agreement and consensus to address climate challenge. American Society of International Law-ASIL Insights 2016; Vol. 20 Issue 8.

[2] United Nations Framework Convention on Climate Change. Paris: Adoption of the Paris Agreement, 12 December; 2015.

[3] Intergovernmental Panel on Climate Change. Climate change 2014: Synthesis report. Contribution to the fifth assessment report of the IPCC. Geneva: IPCC; 2014.

[4] European Environment Agency. Final energy consumption by sector and Fuel. Copenhagen: European Environment Agency; 2015.

[5] Lau LS, Choong CK, Eng YK. Investigation of the Environmental Kuznets Curve for carbon emissions in Malaysia: Do foreign direct investment and trade matter? Energy Policy 2014; 68: 490-7.

[6] Nejat P, Jomehzadeh F, Taheri MM, Gohari M, Majid MZA. A global review of energy consumption, $\mathrm{CO}_{2}$ emissions and policy in the residential sector (with an overview of the top ten $\mathrm{CO}_{2}$ emitting countries). Renewable and Sustainable Energy Reviews 2015; 43: 843-62.

[7] Štreimikienè D. Residential energy consumption trends, main drivers and policies in Lithuania. Renewable and Sustainable Energy Reviews 2014;35:285-93.

[8] Heinonen J, Junnila S. Residential energy consumption patterns and the overall housing energy requirements of urban and rural households in Finland. Energy and Buildings 2014; 76: 295-303. 
[9] Wiedenhofer D, Lenzen M, Steinberger JK. Energy requirements of consumption: Urban form, climatic and socio-economic factors, rebounds and their policy implications. Energy Policy 2013; 63: 696-707.

[10] Piaggio M, Padilla E. $\mathrm{CO}_{2}$ emissions and economic activity: Heterogeneity across countries and non-stationary series. Energy Policy 2012; 46: 370-81.

[11] Rabe-Hesketh S, Skrondal A. Multilevel and longitudinal modeling using Stata. College Station, Texas: Stata Press; 2008.

[12] West BT, Galecki AT. An overview of current software procedures for fitting linear mixed models. The American Statistician 2011; 65(4): 274-82.

[13] Leckie G, French R, Charlton C, Browne W. Modeling heterogeneous variancecovariance components in two-level models. Journal of Educational and Behavioral Statistics 2014; 39(5): 307-32.

[14] Pablo-Romero M, Sánchez-Braza A. Productive energy use and economic growth: Energy, physical and human capital relationships. Energy Economics 2015;49:420-9.

[15] Chowdhury R, Moran E. Turning the curve: A critical review of Kuznets approaches. Applied Geography 2012; 32(1): 3-11.

[16] Fujii H, Managi S. Which industry is greener? An empirical study of nine industries in OECD countries. Energy Policy 2013; 57: 381-8.

[17] Wang L, Ding X, Wu X. Environmental Kuznets curve for pollutants emissions in China's textile industry: An empirical investigation. International Journal of Environmental Technology and Management 2014; 17(1): 14-29.

[18] $\mathrm{Fu} \mathrm{J}$, Zhang $\mathrm{C}$. International trade, carbon leakage, and $\mathrm{CO}_{2}$ emissions of manufacturing industry. Chinese Journal of Population Resources and Environment 2015; 13(2): 139-45.

[19] Cole M, Rayner A, Bates J. The environmental Kuznets curve: An empirical analysis. Environment and Development Economics 1997; 2(4): 401-16.

[20] Hilton F, Levinson A, Factoring the environmental Kuznets curve: Evidence from automotive lead emissions. Journal of Environmental Economics and Management 1998; 35(2): 126-41.

[21] Cox A, Collins A, Woods L, Ferguson N. A household level environmental Kuznets curve? Some recent evidence on transport emissions and income. Economics Letters 2012; 115(2): 187-9.

[22] Abdallah K, Belloumi M, Wolf D. Indicators for sustainable energy development: A multivariate cointegration and causality analysis from Tunisian road transport sector. Renewable and Sustainable Energy Reviews 2013; 25: 34-43.

[23] Chandran V, Tang C. The impacts of transport energy consumption, foreign direct investment and income on $\mathrm{CO}_{2}$ emissions in ASEAN-5 economies. Renewable and Sustainable Energy Reviews 2013; 24: 445-53.

[24] Azlina A, Law S, Mustapha N. Dynamic linkages among transport energy consumption, income and $\mathrm{CO}_{2}$ emission in Malaysia. Energy Policy 2014; 73: 598-606.

[25] Shahbaz M, Khraief N, Jemaa MMB. On the causal nexus of road transport $\mathrm{CO}_{2}$ emissions and macroeconomic variables in Tunisia: Evidence from combined cointegration tests. Renewable and Sustainable Energy Reviews 2015; 51: 89-100.

[26] Coderoni S, Esposti R. Is there a long-term relationship between agricultural GHG emissions and productivity growth? A dynamic panel data approach. Environmental and Resource Economics 2014; 58(2): 273-302. 
[27] Wei X, Peng J, Cao L. An empirical study of the relationship between agriculture environmental efficiency and economic growth. Modern Economy 2014; 5(5): 598608.

[28] Liutao L. Verification of EKC relation between economic growth and agricultural diffused pollution: An analysis based on inter-provincial panel data. In Qu F. et al., editors. Ecological Economics and Harmonious Society, Singapore: Springer; 2016 p. 159-70.

[29] Bohne RA, Huang L, Lohne J. A global overview of residential building energy consumption in eight climate zones. International Journal of Sustainable Building Technology and Urban Development 2016; 7(1): 38-51.

[30] Yin H, Zhou H, Zhu K. Long-and short-run elasticities of residential electricity consumption in China: A partial adjustment model with panel data. Applied Economics 2015; 48(28): 2587-99.

[31] Narayan PK, Narayan S. Carbon dioxide emissions and economic growth: Panel data evidence from developing countries. Energy Policy 2010; 38(1); 661-6.

[32] Narayan PK, Saboori B, Soleymani A. Economic growth and carbon emissions. Economic Modelling 2016; 53: 388-97.

[33] Pablo-Romero M., Sánchez-Braza A, González-Limón JM. Covenant of Mayors: Reasons for being an environmentally and energy friendly municipality. Review of Policy Research 2015; 32(5): 576-99

[34] De la Fuente A. Una función de producción translog para las regiones Españolas: Notas preliminares. Documento de Trabajo D-2008-06. Madrid: Dirección General de Presupuestos, Ministerio de Economía y Hacienda; 2008.

[35] Stern D. The environmental Kuznets curve: A primer. CCEP Working Paper 1404. Canberra: Centre for Climate Economic \& Policy, Crawford School of Public Policy, The Australian National University; 2014.

[36] Pesaran MH. General diagnostic tests for cross section dependence in panels. Cambridge Working Papers WP0435. Cambridge: Faculty of Economics, University of Cambridge; 2004.

[37] Pesaran MH. A simple panel unit root test in the presence of cross section dependence, Journal of Applied Econometrics 2007; 22(2): 265-312.

[38] Westerlund J. Testing for error correction in panel data. Oxford Bulletin of Economics and Statistics 2007; 69(6): 709-48.

[39] Persyn D, Westerlund J. Error-correction-based cointegration tests for panel data. The Stata Journal 2008; 8(2): 232-41.

[40] Anjum Z, Burke P, Gerlagh R, Stern D.Modeling the emissions-income relationship using long-run growth rates. CCEP Working Paper 1403. Canberra: Centre for Climate Economic \& Policy, Crawford School of Public Policy, The Australian National University; 2014.

[41] Hsiao C, Mountain DC, Ho-Illman K. Bayesian integration of end-use metering and conditional demand analysis. Journal of Business and Economic Statistics 1995; 13(3): 315-26.

[42] Dinda S. Environmental Kuznets curve hypothesis: A survey. Ecological Economics 2004; 49(4): 431-55.

[43] International Energy Agency. Statistics report, energy balances. Paris: OECD/IEA; 2016.

[44] The World Bank. World development indicators. Washington DC: The World Bank; 2016. 
[45] Wooldridge J. Econometric analysis of cross section and panel data. Massachusetts: MIT Press; 2002.

[46] Greene W. Econometric analysis. 4th ed. Upper Saddle River: Prentice Hall; 2000.

[47] Vassileva I, Campillo J. Increasing energy efficiency in low-income households through targeting awareness and behavioral change. Renewable Energy 2014; 67, 59-63.

[48] Cayla JM, Maizi N, Marchand C. The role of income in energy consumption behaviour: Evidence from French households data. Energy Policy 2011; 39(12): 7874-83.

[49] Mata É, Kalagasidis AS, Johnsson F. Cost-effective retrofitting of Swedish residential buildings: Effects of energy price developments and discount rates. Energy Efficiency 2015; 8(2): 223-37.

[50] Bartiaux F, Schmidt L, Horta A, Correia A. Social diffusion of energy-related practices and representations: Patterns and policies in Portugal and Belgium. Energy Policy 2016; 88: 413-21.

[51] ADEME. Energy efficiency trends and policies in the household and tertiary sectors. Paris: ADEME; 2015.

[52] Galvin R. Estimating broad-brush rebound effects for household energy consumption in the EU 28 countries and Norway: Some policy implications of Odyssee data. Energy Policy 2014; 73: 323-32.

[53] Filipović S, Verbič M, Radovanović M. Determinants of energy intensity in the European Union: A panel data analysis. Energy 2015; 92(3): 547-55.

[54] Bouzarovski S, Herrero ST. 2015. The energy divide: Integrating energy transitions, regional inequalities and poverty trends in the European Union. European Urban and Regional Studies 2015; in press.

[55] Filippini M, Hunt LC, Zorić J. Impact of energy policy instruments on the estimated level of underlying energy efficiency in the EU residential sector. Energy Policy 2014; 69: 73-81.

[56] Sánchez-Braza A, Pablo-Romero MP. Evaluation of property tax bonus to promote solar thermal systems in Andalusia (Spain). Energy Policy 2014; 67: 832-43.

[57] Rai V, Sigrin B. Diffusion of environmentally-friendly energy technologies: Buy versus lease differences in residential PV markets. Environmental Research Letters 2013; 8(1): 014022. 


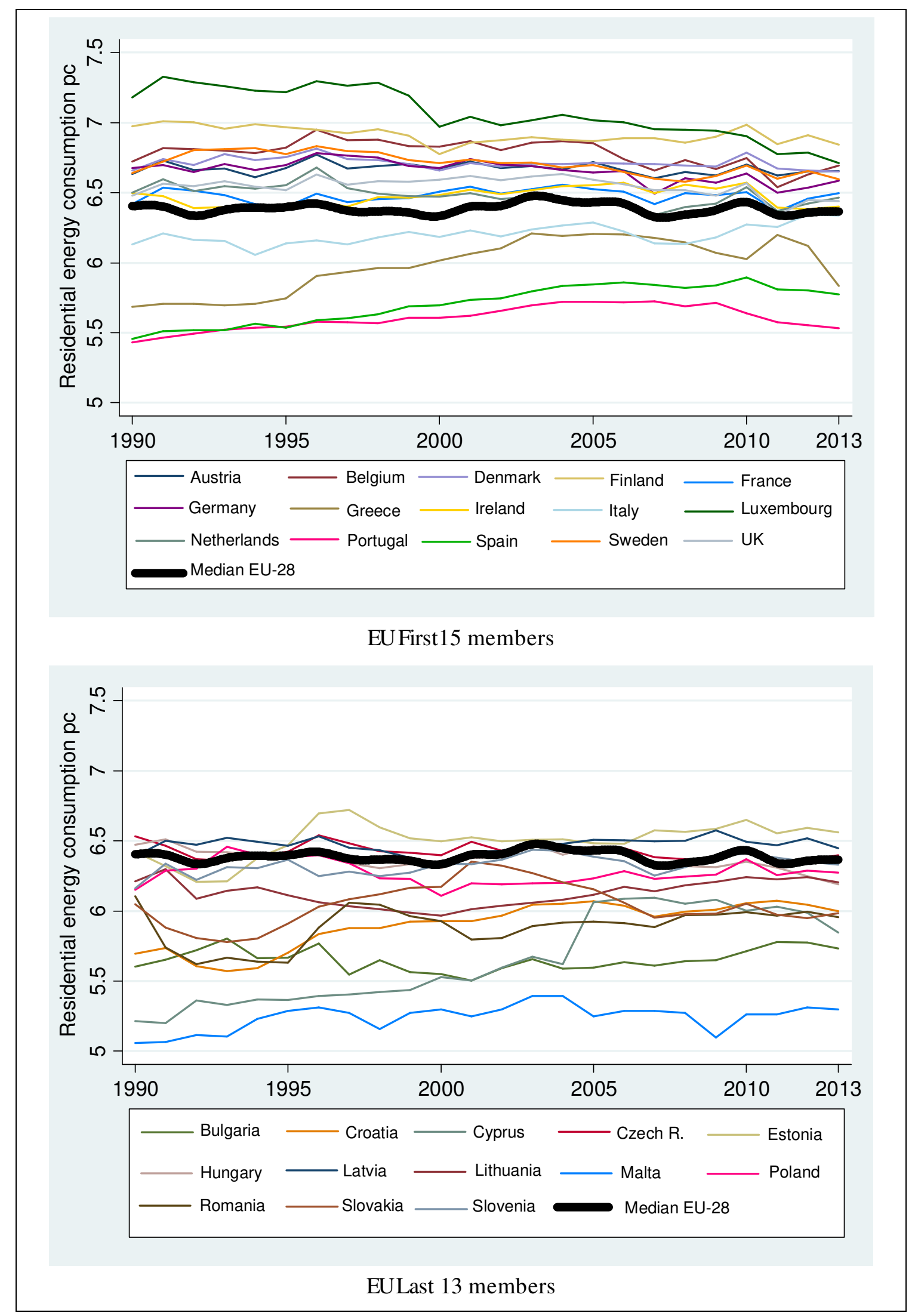

Fig. 1. Residential energy consumption per capita (in logs) evolution by country (1990-2013). 


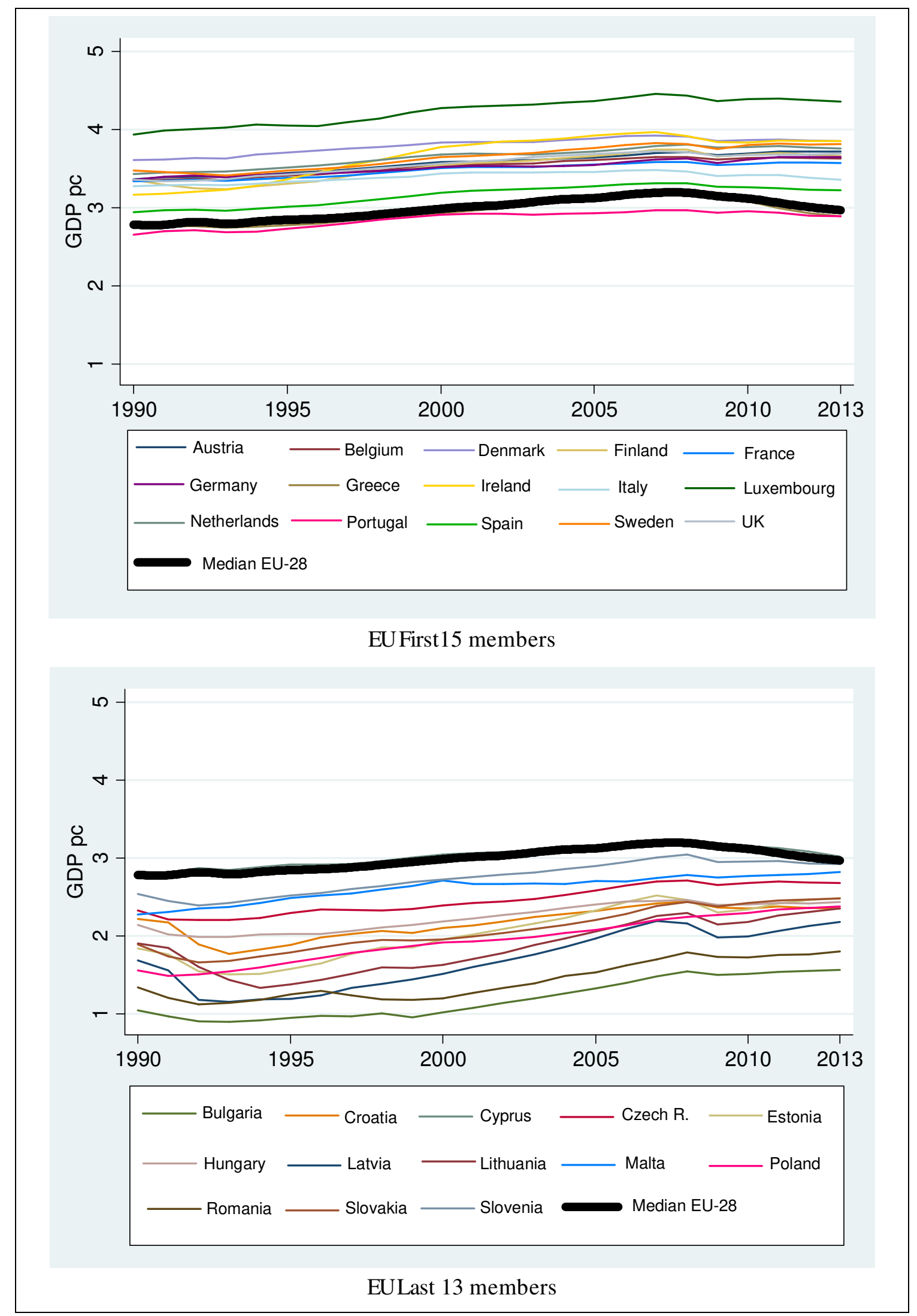

Fig. 2. Gross Domestic Product per capita (in logs.) evolution by country (1990-2013). 


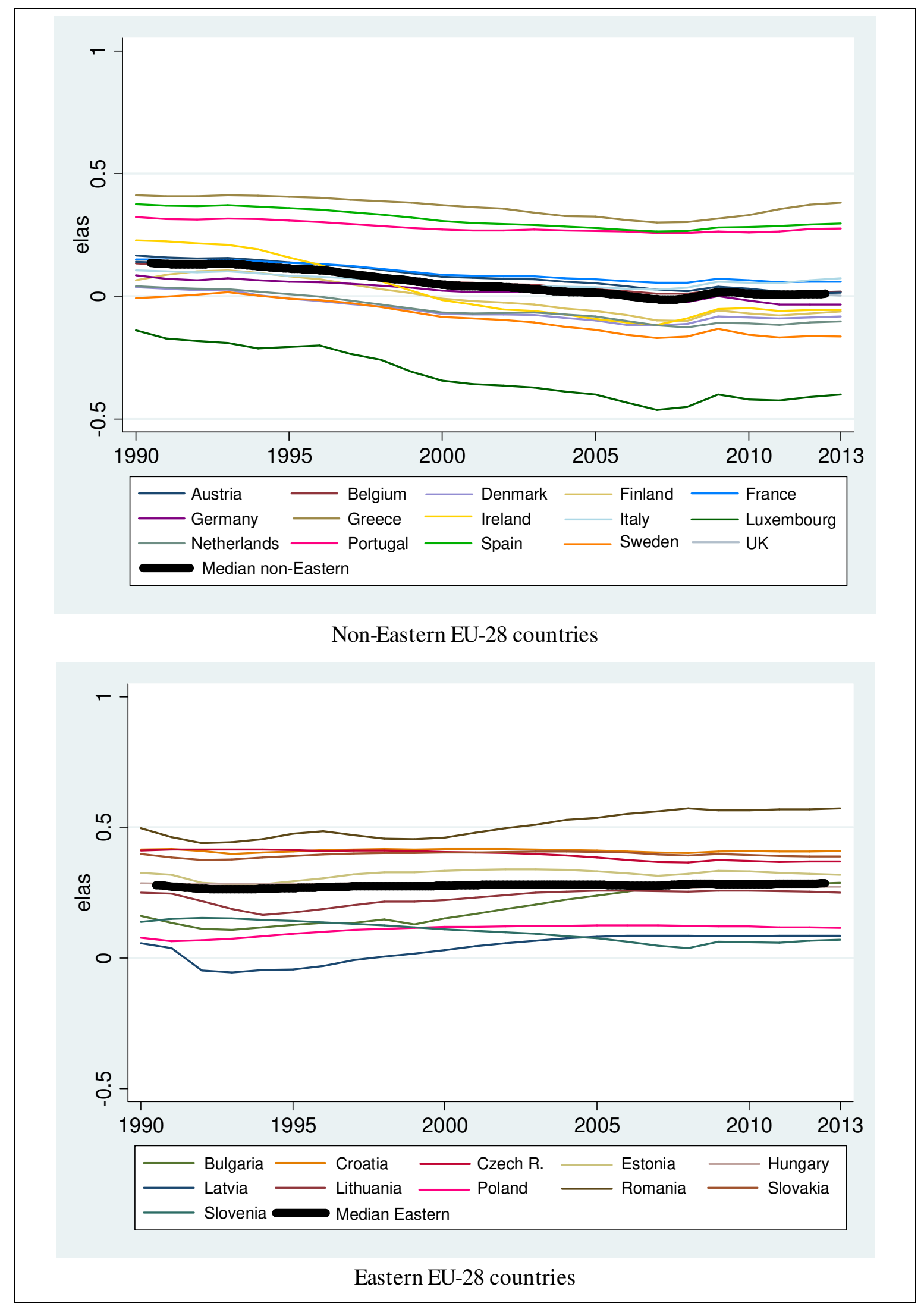

Fig. 3. Residential energy consumption per capita with respect to GDP per capita elasticities evolution by country (1990-2013). 


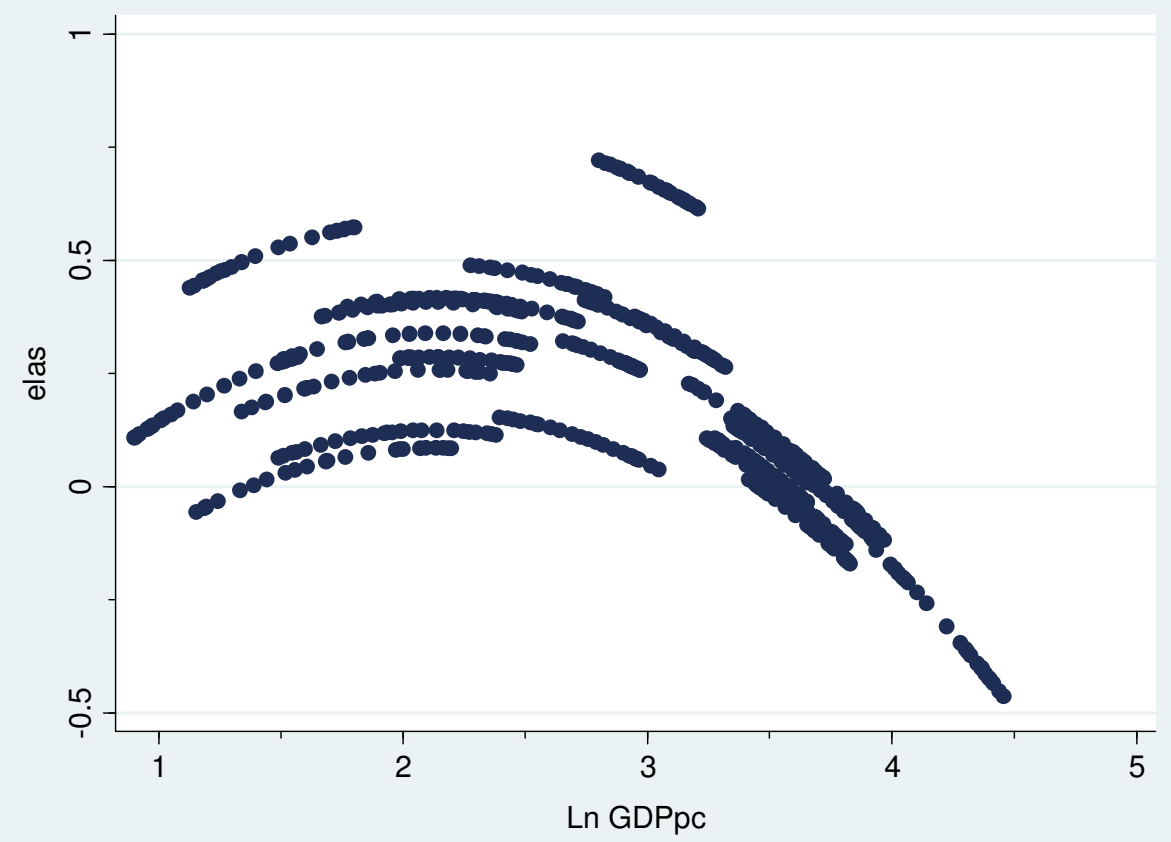

Fig. 4. Estimated residential energy consumption per capita with respect to GDP per capita elasticities by GDP per capita level. 